\title{
GAMMA-RAY SPECTROMETRY WITH THICK MERCURIC IODIDE DETECTORS*
}

by

A. Beyerle, K. Hull, J. Markakis, and B. Lopez

EGEGG, Santa Barbara Operations

Goleta, California 93116

and

W.M. Szymczyk

Institute for Physics and Imaging Science

University of Southern California, Marina del Rey, California 90291

\section{ABSTRACT}

Gamma-ray spectra with energies up to $1.3 \mathrm{MeV}$ have been detected for the first time with $1-\mathrm{cm}-$ thick $\mathrm{HgI}_{2}$ semiconductor detectors at room temperature. The spectra can be taken using a "long," $10 \mu \mathrm{s}$, or a "short," $0.5 \mu \mathrm{s}$, charge collection time. The latter has produced better results with better peak efficiency, higher peak-to-valley ratio, and fewer low energy counts with little sacrifice in resolution. Spectra for energies between $100 \mathrm{keV}$ and $1.3 \mathrm{MeV}$ and descriptions of the techniques for their acquisition are presented. The thick detectors need a conditioning treatment, which is described, prior to showing spectral response.

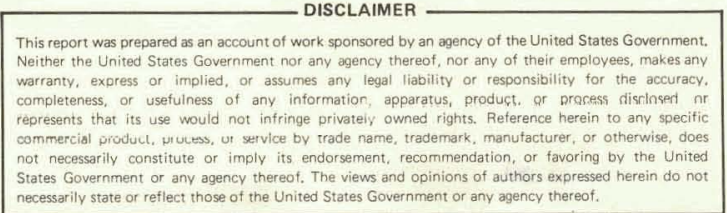

*This work was performed under the auspices of the U.S. Department of Energy under Contract No. DE-AC08-76NV01183. NOTE: By acceptance of this article, the publisher and/or recipient acknowledges the U.S. Government's right to retain a nonexclusive royalty-free license in and to any copyright covering this paper.

Reference to a company or product name does not imply approval or recommendation of the product by the U.S. Department of Energy to the exclusion of others that may be suitable. 


\section{DISCLAIMER}

This report was prepared as an account of work sponsored by an agency of the United States Government. Neither the United States Government nor any agency Thereof, nor any of their employees, makes any warranty, express or implied, or assumes any legal liability or responsibility for the accuracy, completeness, or usefulness of any information, apparatus, product, or process disclosed, or represents that its use would not infringe privately owned rights. Reference herein to any specific commercial product, process, or service by trade name, trademark, manufacturer, or otherwise does not necessarily constitute or imply its endorsement, recommendation, or favoring by the United States Government or any agency thereof. The views and opinions of authors expressed herein do not necessarily state or reflect those of the United States Government or any agency thereof. 


\section{DISCLAIMER}

Portions of this document may be illegible in electronic image products. Images are produced from the best available original document. 


\section{GAMMA-RAY SPECTROMETRY WITH THICK MERCURIC \\ IODIDE DETECTORS*}

by

A. Beyerle, K. Hull, J. Markakis, B. Lopez

EG\&G Inc., Santa Barbara, CA 93116, USA

and

W.M. Szymczyk,

Institute for Physics and Imaging Science, Marina Del Rey, CA 90291, USA

\section{ABSTRACT}

Gamma-ray spectra with energies up to $1.3 \mathrm{MeV}$ have been detected for the first time with 1 -cm-thick $\mathrm{HgI}_{2}$ semiconductor detectors at room temperature. The spectra can be taken using a "long," $10 \mu \mathrm{sec}$, or a "short," $0.5 \mu \mathrm{sec}$, charge collection time. The latter has produced better results with better peak efficiency, higher peak-to-valley ratio, and fewer low energy counts with little sacrifice in resolution. Spectra for energies between $100 \mathrm{keV}$ and $1.3 \mathrm{MeV}$ and descriptions of the techniques for their acquisition are presented. The thick detectors need a conditioning treatment, which is described, prior to showing spectral response.

\section{INTRODUCTION}

Mercuric iodide is a wide-band-gap semiconductor of $2.1 \mathrm{eV}$ and therefore can be used as a room-temperature $x$-ray and gamma-ray spectrometer. Crystals of

\footnotetext{
*This work was performed under the auspices of the U.S. Department of Energy under Contract No. DE-AC08-76NV0118j. NOTE: By acceptance of this article, the publisher and/or recipient acknowledges the U.S. Government's right to retain a nonexclusive royalty-free $1 \mathrm{icense}$ in and to any copyright covering this paper.

Reference to a company or product name does not imply approval or recomendation of the product by the U.S. Department of Energy to the exclusion of others that may be suitable. 
$\mathrm{Hgi}_{2}$ grown so far have allowed for the fabrication of efficient $x$-ray spectrometers with excellent resolution: ${ }^{1}$ thin gamma-ray spectrometers with good resolution but low efficiency of $0.5-1.0 \mathrm{~mm}$ thickness, ${ }^{2}$ or thick gamma-ray counters of about $10 \mathrm{~mm}$ thickness ${ }^{3}$ which have good efficiency but no spectral resolution. The study. of thick $\mathrm{HgI}_{2}$ counters for use as spectrometers revealed that with proper conditioning and treatment of output waveforms, valuable spectroscopic information can result. The purpose of this paper is to describe the preliminary results obtained for the first time with these thick detectors, including an energy determination technique applied for the first time to mercuric iodide with promising results.

\section{DETECTOR FABRICATION}

Large sample crystals of $\mathrm{HgI}_{2}$ weighing up to $400 \mathrm{~g}$ are being grown at EG\&G from the vapor phase by a method described elsewhere. ${ }^{4}$ The crystals are sawn into blocks having active areas from 2 to $10 \mathrm{~cm}^{2}$ and thicknesses from 0.4 to $4.7 \mathrm{~cm}$. Most of the results presented here are based on experiences with $1-\mathrm{cm}-\mathrm{thick}$ detectors. The electrodes are either painted on aquadag or on vacuum-deposited palladium contacts. Fabrication details are presented elsewhere. ${ }^{2}$

\section{CONDITIONING}

Conditioning techniques have been developed which dramatically increasc the spectral resolution and peak efficiency of the thick detectors. The conditioning effect has been noticed for thin detectors, 5 but becomes a critical factor in the operation of $1-\mathrm{cm}-$ thick spectrometers. Their output exhibits a characteristic settling time period which must elapse for the detector output to stabilize following application of bias. A period of rapid improvement takes place, with a duration which ranges from about one day to about a week. Detector response often continues to improve more slowly over a period of weeks to several months. Figure 1 is a comparison of spectra taken a few hours after turn on and many days after. During the settling period, charge collection efficiency increases, leakage current 
decreases, and the low-energy noise decreases. During this conditioning time, spectra usually have better resolution and peak efficiency if the detector is irradiated with penetrating gamma radiation for several days before the spectra are taken. Preliminary results indicate that a conditioning effect also takes place if small amounts of visible light are introduced while the detector is under bias. We accomplish this with a pulsed LED. Positive effects are observed even though the light cannot penetrate the crystal.

The spectra have been taken in the usual way, ${ }^{2}$ but with two variations in technique: one uses a long charge collection time and the other very short charge collection time. These techniques and the results obtained with each are described next.

\section{LONG CHARGE COLLECTION TIME}

The usual approach of using shaping times long enough to collect as much charge as possible has been utilized with the thick spectrometers. With ficld strength of about $E=5 \times 10^{3} \mathrm{~V} / \mathrm{cm}$ and hole mobilities on the order of $\mu=4 \mathrm{~cm} / \mathrm{V}-\mathrm{sec}$, we cannot expect to collect many of the holes. The transit time $T_{r}$ which the holes will take to traverse the crystal at these biases $\mathrm{T}_{\mathrm{r}}=\mathrm{L} /(\mu \mathrm{E})$ for $\mathrm{L}=1 \mathrm{~cm}$ is roughly $50 \mu \mathrm{sec}$. Even if it were reasonable to use amplifier shaping times this long, it would not be effective because the holc trapping time $T_{h} \simeq 10 \mu \mathrm{sec}$ is shorter than $T_{r}$. Electrons, on the other hand, have a mobility on the order of $100 \mathrm{~cm} / \mathrm{V}-\mathrm{sec}$ which results in a transit time $\mathrm{T}_{\mathrm{r}}=2 \mathrm{\mu sec}$, which is much shorter than the electron trapping time $\mathrm{T}_{\mathrm{c}}>400$ usec." Thercforc, using shaping timcs long compared to $\mathrm{T}_{\mathrm{r}}$ for clectrons will result in good electron collection. However, even using shaping times on the order: of $r_{r}$ for holes will not yield good hole collection because $T_{h}$ if too short. We have used amplifier shaping times as long as $50 \mu \mathrm{sec}$, but have found that shaping times of about $10 \mu \mathrm{sec}$ produce the best results; $10 \mathrm{\mu sec}$ is larger than the time needed 
to collect the electrons and is on the order of $T_{h}$, while the $50 \mu$ sec time collects more holes and also increases noise. Examples of spectra taken with long charge collection times are shown in Figure $1-4$.

Low-energy irradiation of the detectors results in spectra which show a clear photopeak. Figure 2 shows a ${ }^{57}$ Co spectrum which has $122-$ and $132-\mathrm{keV}$ gammarays. Detectors are irradiated through the negative electrode, so at these energies $95 \%$ of the interactions take place in the first $2.5 \mathrm{~mm} .^{7}$ Hole collection through this distance is not unreasonable, since for this short distance $T_{e}, T_{h}>T_{r}$ for both electrons and holes, so that these spectra represent a reasonable portion of the charge collected. Even if the holes are not collected, the distance they need to travel is so small that they represent only a small fraction of the charge induced on the electrodes. For these energies, the detector can be thought of as a thin irradiated volume with a large shielded volume behind. Hence, we get spectra similar in features to a thin detector spectrum; however, the resolution is not as good as for thin detectors but is generally still better than $10 \%$. Compton scattering is quite small at these energies, which results in quite a clean photoelectric spectrum. If the detector is irradiated through the positive electrode, the spectra are much worse. This is because the holes produced near the positive electrodes cannot traverse the entire crystal, so that the charge collection efficiency is much worse. For all energies the results are better if the detectors are irradiated through the negative contact. This effect is less pronounced at higher energies because the detector is more uniformly irradiated at higher cncrgics.

For moderately high energies, the $1-\mathrm{cm}$-thick crystals are irradiated all the way through. Figure 3 shows a ${ }^{133} \mathrm{Ba}$ spectrum which has several gamma photopeaks $(81,276,303,356$, and $384 \mathrm{keV})$. The low-energy peak is quite prominent, and the stronger high-energy peaks are easily distinguishable. The ${ }^{1.57}$ is spectrum 
in Figure 4 also shows a nice photopeak $(E=662 \mathrm{keV})$. Resolutions are generally less than $10 \%$ as measured as full width at half maximum (FWHM) above the continuum.

At the highest energies measured (Figure 5) for ${ }^{60} \mathrm{Co}(E=1.17$ and $1.33 \mathrm{MeV}$ ), full energy peaks are still visible, although their peak efficiency is quite low. In all spectra, features are visible which can be used to discriminate this source from others. For these energies the detector is more uniformly irradiated.

Efficiency measurements for the penetrating radiation indicate that the entire crystal volume is active. For the low-energy radiation, the crystal is $100 \%$ efficient. At higher energies, total count rates agree well with those predicted with total mass absorbtion coefficients of $\mathrm{HgI}_{2}$.

\section{SHORT CHARGE COLLECTION TIMES}

Another technique we have developed ${ }^{8}$ to extract energy information from the detector is to collect charge for a period of time which is short compared to the carrier transit time $\mathrm{T}_{\mathrm{r}}$. Charge carriers will induce a charge on the electrodes proportional to their distance of travel through the detector. The charge, $Q$, induced is $Q=n_{e} e \Delta X_{e} / L+n_{h} e \Delta X_{h} / L$ where $n_{e, h}$ is the number of electrons and holes produced, e is the electron charge, and $\Delta x_{e}, \Delta x_{h}$ is the distance traveled by electrons and holes, respectively. The rate at which the charge carriers move depends on their mobility and the electric field inside the crystal. If the detector material and electric field is uniform, the carrier velocitics will bc constant. Therefore, for a fixed charged collection time the charge collected will be proportional to the number of electron-hole pairs free to drift, and hence proportional to the energy deposited by the interaction.

The short charge collection time technique depends on the carricrs being free to drift under the influence of the electric field during the charge collection time. Charge collection time can be chosen short compared to the trapping times 
$T_{e}$ and $T_{h}$. However, there exists a dead layer in the crystal near the positive electrode, because electrons created in this region will strike the electrode and cease to induce charge within the collection time. The charge collection time must be chosen as short as is practical to minimize this dead layer. The same effect exists for holes, but since their mobility is much lower than that of electrons the effect is small.

Since all of the available charge is not being collected by this technique, the signal output is more heavily influenced by detector preamplifier noise. The choice of operating parameters is very important to obtain a compromise between signal-to-noise ratio and the condition that the carriers remain free (are not "collected") in the charge collection time. The condition that the carriers are not collected creates a dead layer near the positive electrode which depends on collection time.

Various means can be used to accomplish the short time charge collection technique. The most successful method uses a standard gaussian amplifier with a short shaping time relative to the charge collection time. This is described more fully in another contribution. ${ }^{6}$ It should be noted that it is the low noisc and low mobilities of mercuric iodide which allow this technique to be used.

Using $1-\mathrm{cm}$-thick detectors, a bias of $5 \mathrm{kV}$ is high enough to producc fairly uniform fields in the detector, yet not too high to cause noise problcms or too short electron transit times. A shaping time of $0.5 \mu \mathrm{sec}$ is optimal for a $5 \mathrm{kV}$ bias, since it allows electron transit of about $20 \%$ of the crystal with negligible trapping losses, yet collects enough charge to reduce noise cffects.

Low-energy spectra show the same characteristics with this technique as for the long charge collection times. Since charge is primarly induced by clectrons for this surface irradiation, we sacrifice only the fraction of elcctron induccd 
charge collected as compared to long shaping times. The ${ }^{57}$ Co spectra in Figure 6 have very few continum counts as there is little Compton scattering. The resolution is about 15\%, which is worse than the long shaping times because less charge. is collected.

For higher energies, the short charge collection time does considerably better than the longer time. Short collection time spectra show better peak efficiencies, less low energy noise, and better peak-to-valley ratios with little or no reduction in resolution. Figure 7 shows a ${ }^{133}$ Ba spectrum with several of the peaks clearly resolved. Figure 8 is a ${ }^{137} \mathrm{Cs}$ spectrum, which shows better peak-to-valley ratio than the long shaping time result in Figure $4 . \mathrm{A}^{60} \mathrm{Co}$ spectrum in Figure 9 shows quite substantial full-energy peaks where only very small peaks exist with the traditional long shaping time technique (Figure 5). Resolutions of almost $10 \%$ measured as above the zero. line FWHM can be obtained, because there is now enough charge induced on the electrodes to make the noise less of a factor. Efficiency measurements indicate that all of the expected number of total counts are obtained. The number of counts under the full-energy peak at $662 \mathrm{keV}$ is about $30 \%$ of the total number of counts. This peak efficiency is higher than the photo-electric cross-section would indicate, so that multiple interaction partial energy deposition events (such as multiple Compton scattering) must be playing a significant role. One would expect multiple interactions to be important for a detector whose total efficiency even for the highest incident energies through the thinnest dimension is $25 \%$. The separation of the peak from the continuum is distinct with a peak-to-valley ratio of about $2.5: 1$.

\section{CONCLUSION}

Mercuric iodide detectors have been demonstrated to be a viable scmiconductor gamma-ray spectrometer for energies above $1 \mathrm{MeV}$. Spectra obtained are close to those obtained by NaI scintillation detectors of similar efficiency. 
This is the first time that crystals of one $\mathrm{cm}$ in thickness have been used to produce full-energy peaks with good efficiency, or in fact any full energy peaks at all. The poor hole mobilities have been used to advantage with the short charge collection time technique. The preliminary results with short charge collection times represent a new area for study with thick detectors. At the present time the limit of thickness for these detectors is not known. All that is required is a uniform field of sufficient strength to induce sufficient charge on the electrodes in a reasonable time. Preliminary results indicate that spectra can be obtained for detectors which are several $\mathrm{cm}$ in thickness.

\section{ACKNOWLEDGMENTS}

The authors wish to thank Carol Ortale for mercuric iodide detector expertise and assistance in working with the thick detectors, Lodewijk van den Berg for sharing his expertise in mercuric iodide crystal properties, and Michael Scheiber for constructive criticism.

\section{REFERENCES}

1. C. Ortale, L. Pagdett, and W. Schnepple, Nucl. Instr. and Meth., this issue.

2. R.C. Whited and M. Scheiber, Nucl. Instr. and Meth. 162 (1979) 113.

3. J. Warren, Nuc1. Instr, and Meth., this issue.

4. M. Scheiber, W.F. Schnepple and L. van den Berg, J. Cryst. Growth $\underline{3.3}$ (1976) 125 .

5. A. Friant, J. Mellet, C. Saliou, T.M. Brahm, IEEE Trans. on Nuci. Sci. NS-27 (1980) 281 . 
6. J.M. Szymczk, A.J. Dabrowski; J.S. Iwanczyk, J.H. Kumiss, G.C. Huth, K. Hul1, A. Beyerle and J. Markakis, Nucl. Instr. and Meth., this issue,

7. H.L. Malm, IEEE Trans. Nucl. Sci. NS-22 (1975) 182.

8. A. Beyerle and K. Hull, EGGG Inc. SANDS Monthly Progress Report for April, 1982 to USDOE/NV, Report \#L-82-228. 
Figure 1. Comparison of ${ }^{137} \mathrm{Cs}$ spectra after detector turn on showing increase in charge collection efficiency and in peak distinction, and decrease in low energy noise. Each successive spectrum is offset by 250 counts to separate the curves.

Figure 2. Long Charge collection time spectra of ${ }^{57}$ Co from the 1 -cm-thick $\mathrm{HgI}_{2}$ detector EGEG S2-28A with a $10-\mu \mathrm{sec}$ amplifier shaping time, 10-minute collection time, with a $1 \mu \mathrm{Ci}$ source $5 \mathrm{~cm}$ distant.

Figure 3. Long Charge collection time spectra of ${ }^{133} \mathrm{Ba}$ from the 1-cm-thick

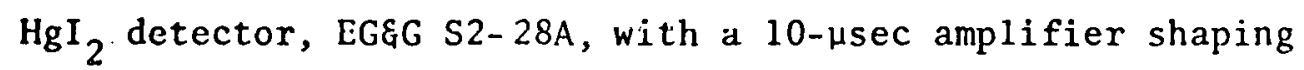
time, 10-minute collection time, with a $1 \mu \mathrm{Ci}$ source $5 \mathrm{~cm}$ distant.

Figure 4. Long Charge collection time spectra of ${ }^{137} \mathrm{Cs}$ from the 1 -cm-thick $\mathrm{HgI}_{2}$ detector, EGEG S2-28A, with a $10-\mu \mathrm{sec}$ amplifier shaping time, 10-minute collection time, with a $1 \mu \mathrm{Ci}$ source $5 \mathrm{~cm}$ distant.

Figure 5. Long Charge collection time spectra of ${ }^{60} \mathrm{Co}$ from the 1-cm-thick $\mathrm{HgI}_{2}$ detector, EG\&G S2-28A, with a $10-\mu \mathrm{sec}$ amplifier shaping rime, 10-minute collection time, with a $1 \mu \mathrm{Ci}$ source $5 \mathrm{~cm}$ distant.

Figure 6. Short Charge collection time spectra of ${ }^{57}$ Co from the 1 -cm-thick $\mathrm{HgI}_{2}$ detector, EG\&G S2-28A, with a $0.5-\mu \mathrm{sec}$ amplifier shaping time, 10-minute collection time, with a $1 \mu \mathrm{Ci}$ source $5 \mathrm{~cm}$ distant. These are the same events in the detector as in Figure 2.

Figure 7. Short Charge collection time spectra of ${ }^{133} \mathrm{Ba}$ from the 1 -cm-thick $\mathrm{HgI}_{2}$ detector, EG\&G S2-28A, with a $0.5-\mu \mathrm{sec}$ amplifier shaping time, 10-minute collection time, with a $1 \mu \mathrm{Ci}$ source $5 \mathrm{~cm}$ distant. These are the same events in the detector as in Figure 3. 
Figure 8. Short Charge collection time spectra of ${ }^{137}$ cs from the $1-\mathrm{cm}$-thick $\mathrm{HgI}_{2}$ detector, EG\&G S2-28A, with a $0.5-\mu \mathrm{sec}$ amplifier shaping time, 10-minute collection time, with a $1 \mu \mathrm{Ci}$ source $5 \mathrm{~cm}$ distant. These are the same events in the detector as in Figure 4.

Figure 9. Short Charge collection time spectra of ${ }^{60}$ Co from the 1-cm-thick $\mathrm{HgI}_{2}$ detector, EG\&G S2-28A, with a $0.5-\mu \mathrm{sec}$ amplifier shaping time, 10-minute collection time, with a $1 \mu \mathrm{Ci}$ source $5 \mathrm{~cm}$ distant. These are the same events in the detector as in Figure 5. 


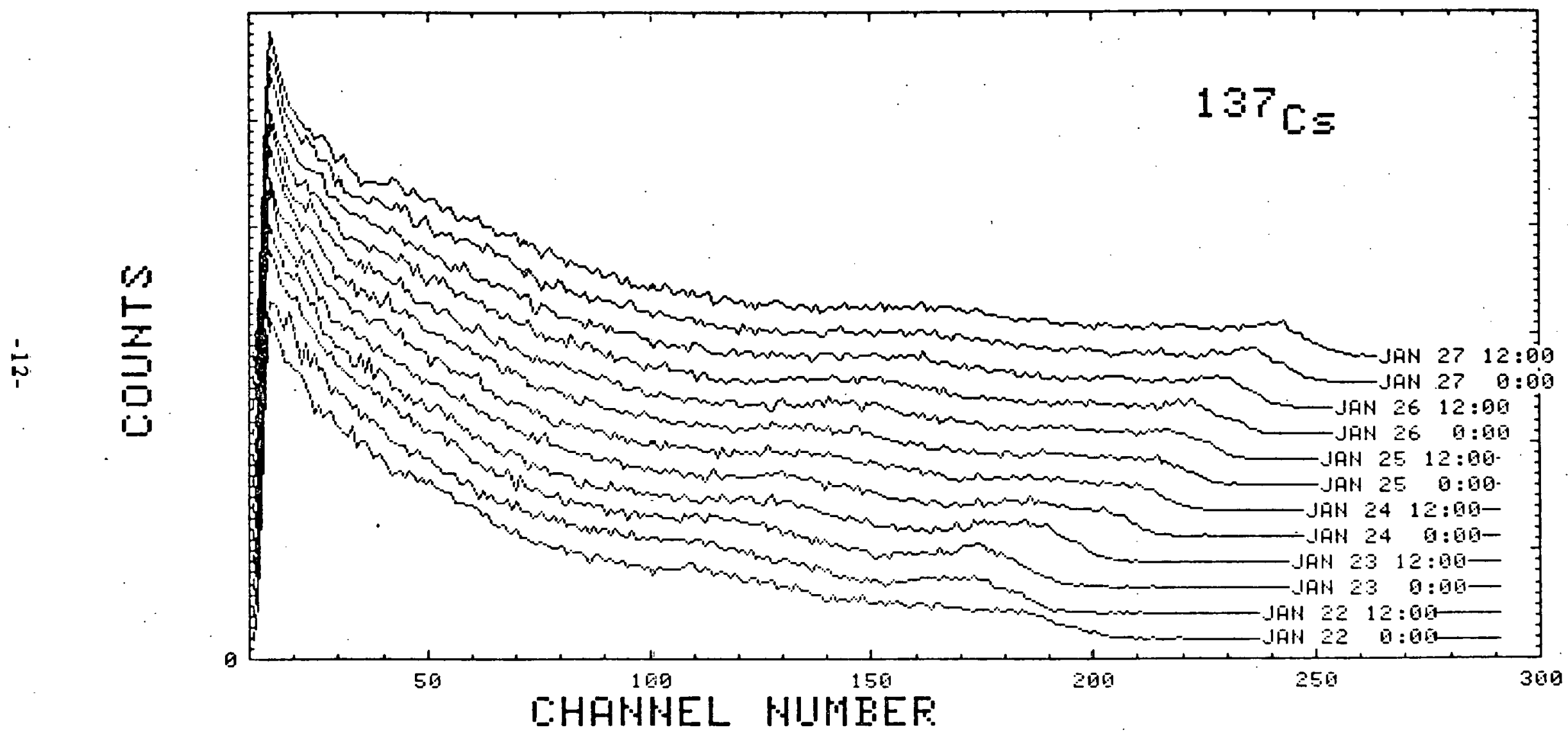

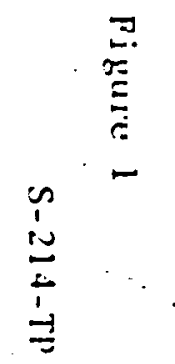




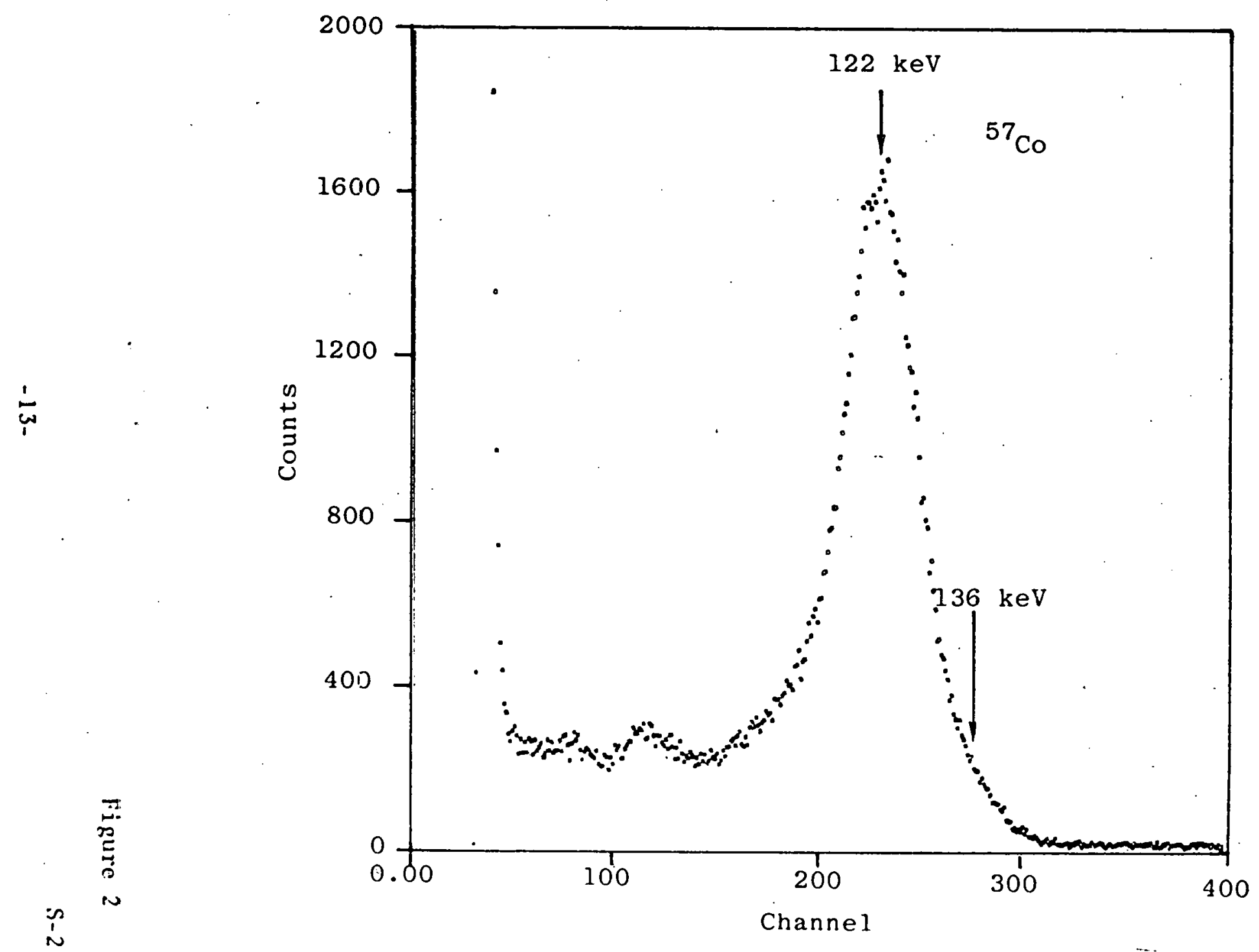


$d L-b I z-S$

\& ว.กรโป

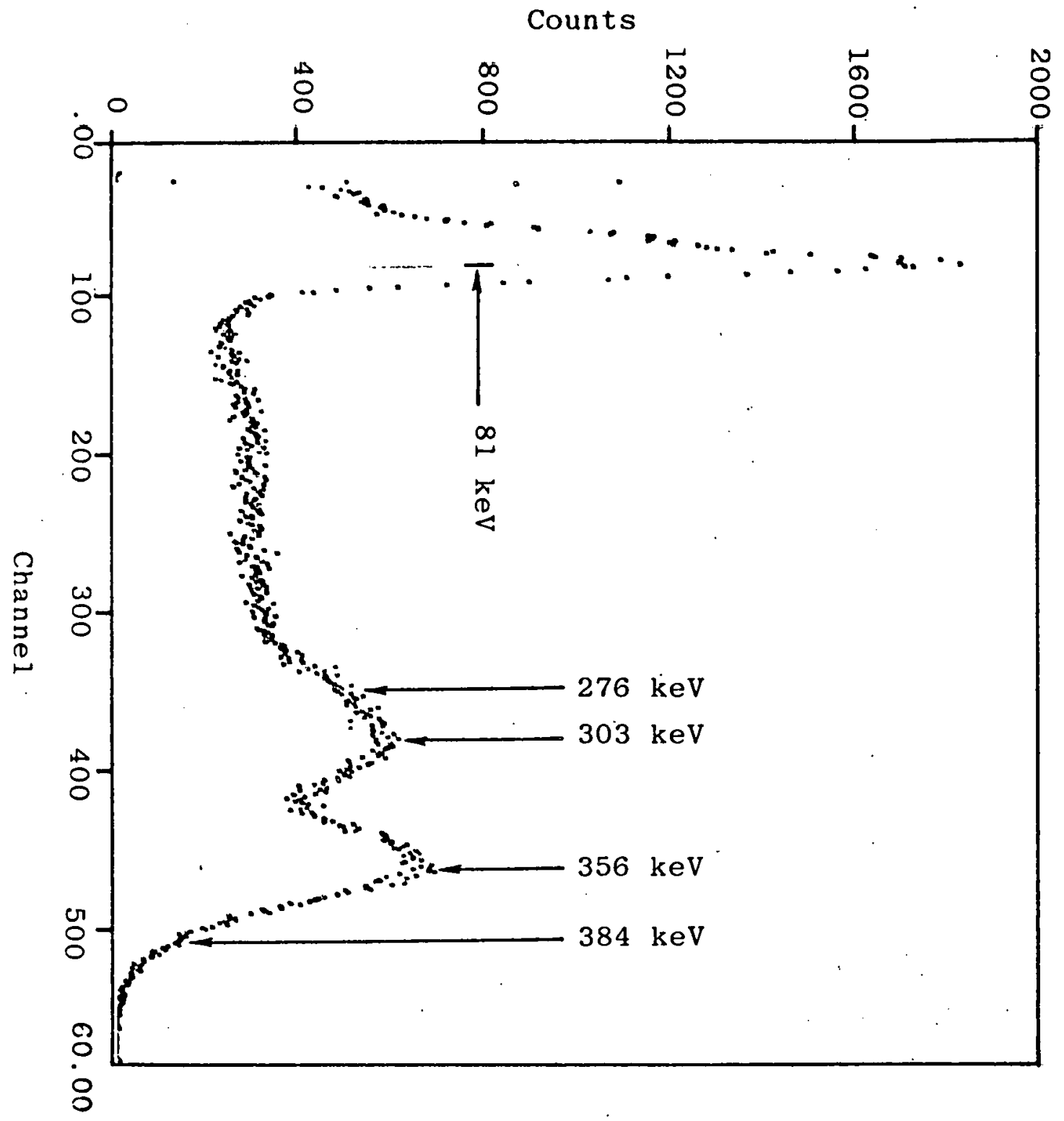




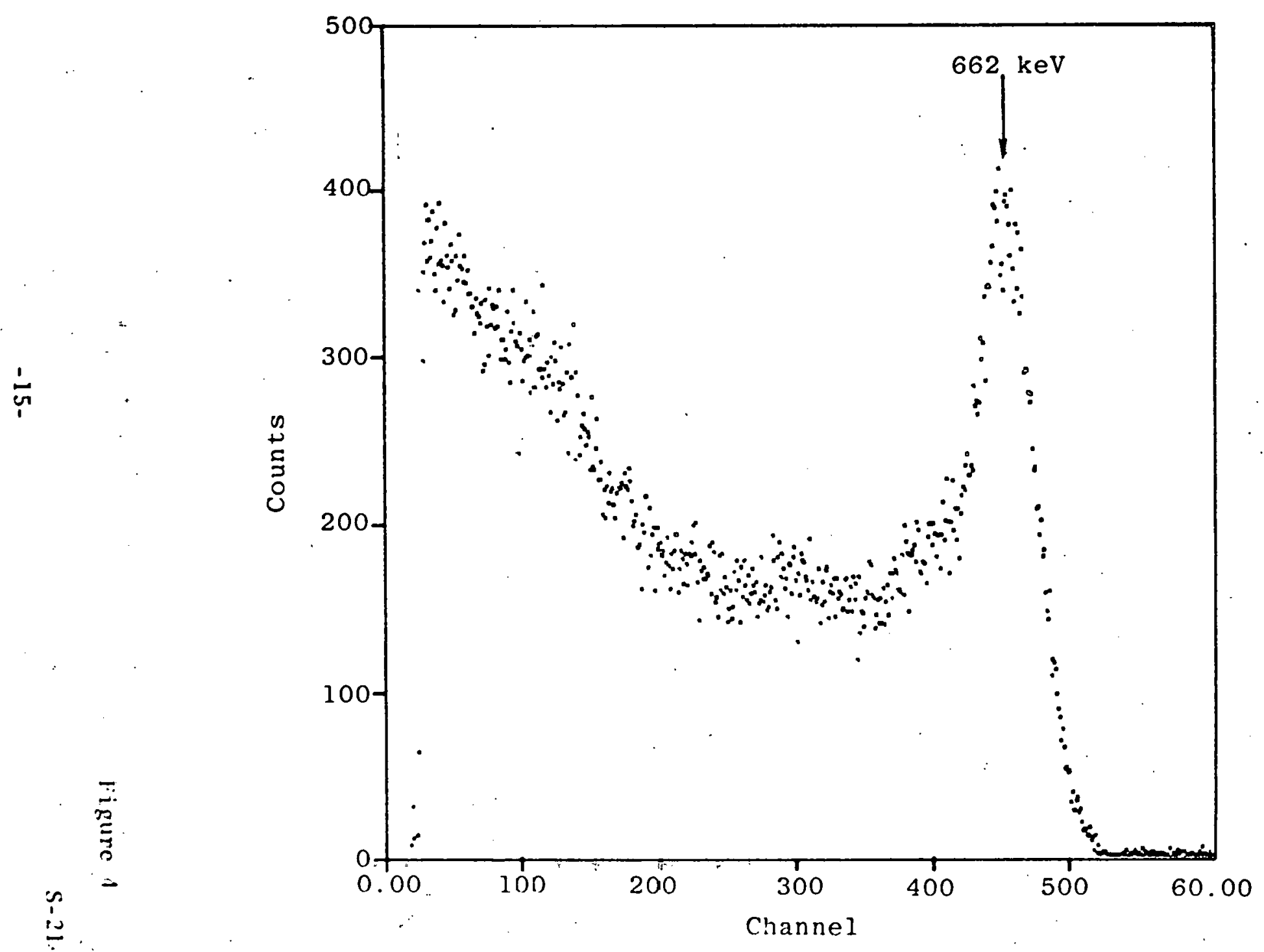




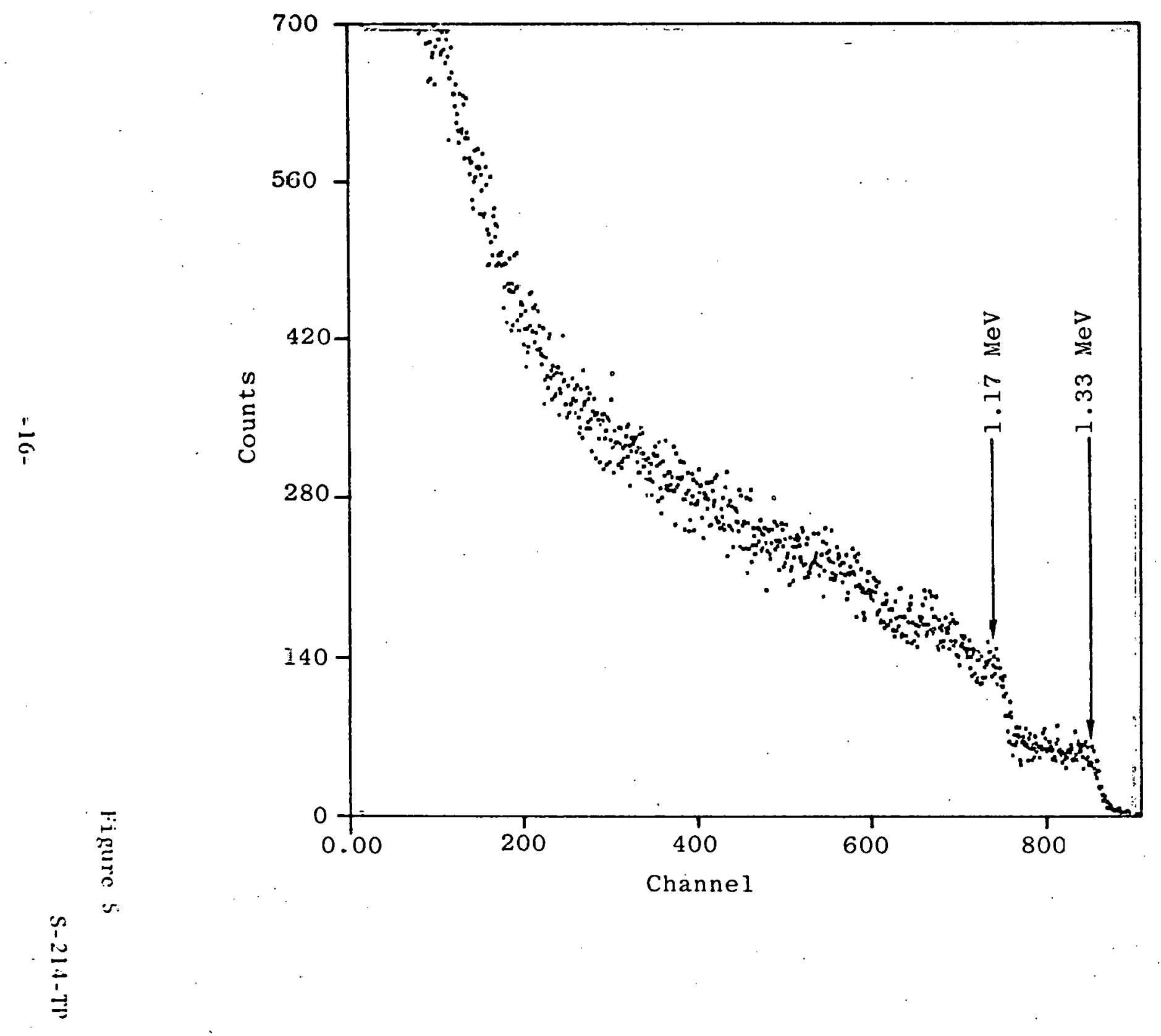




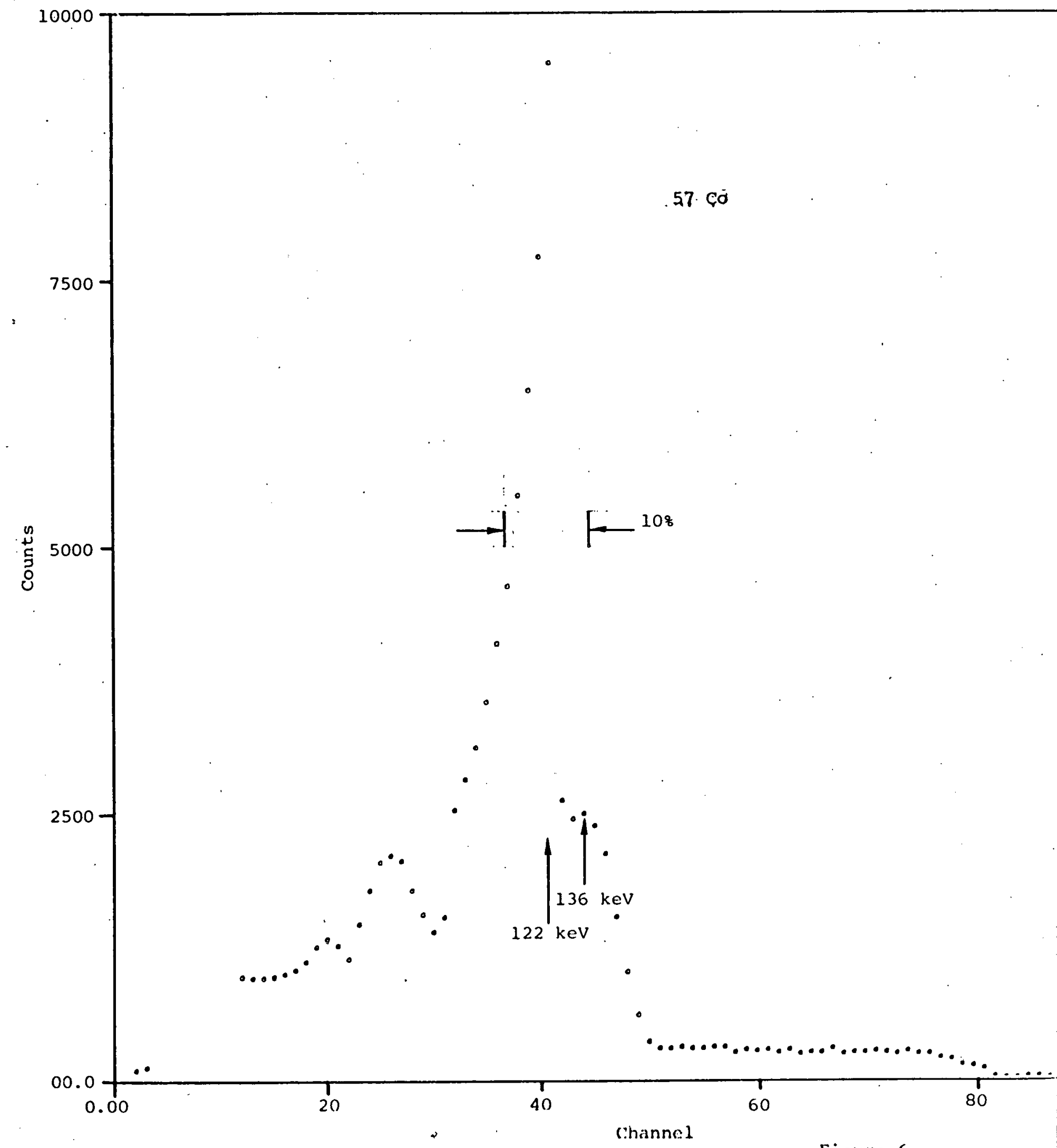

Figure 6 
d]. $-12-s$

$\angle$ o.t118 ! d

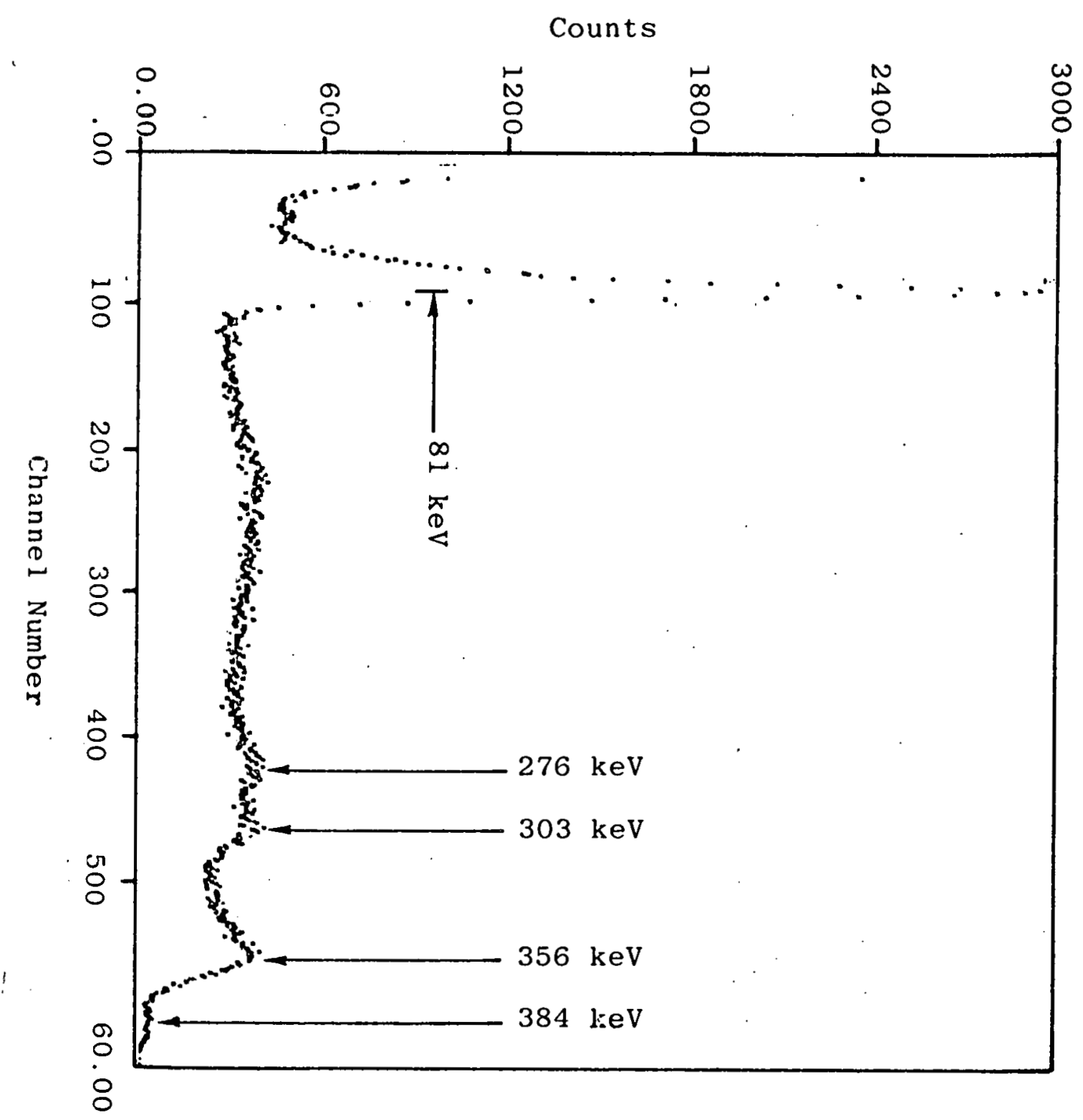




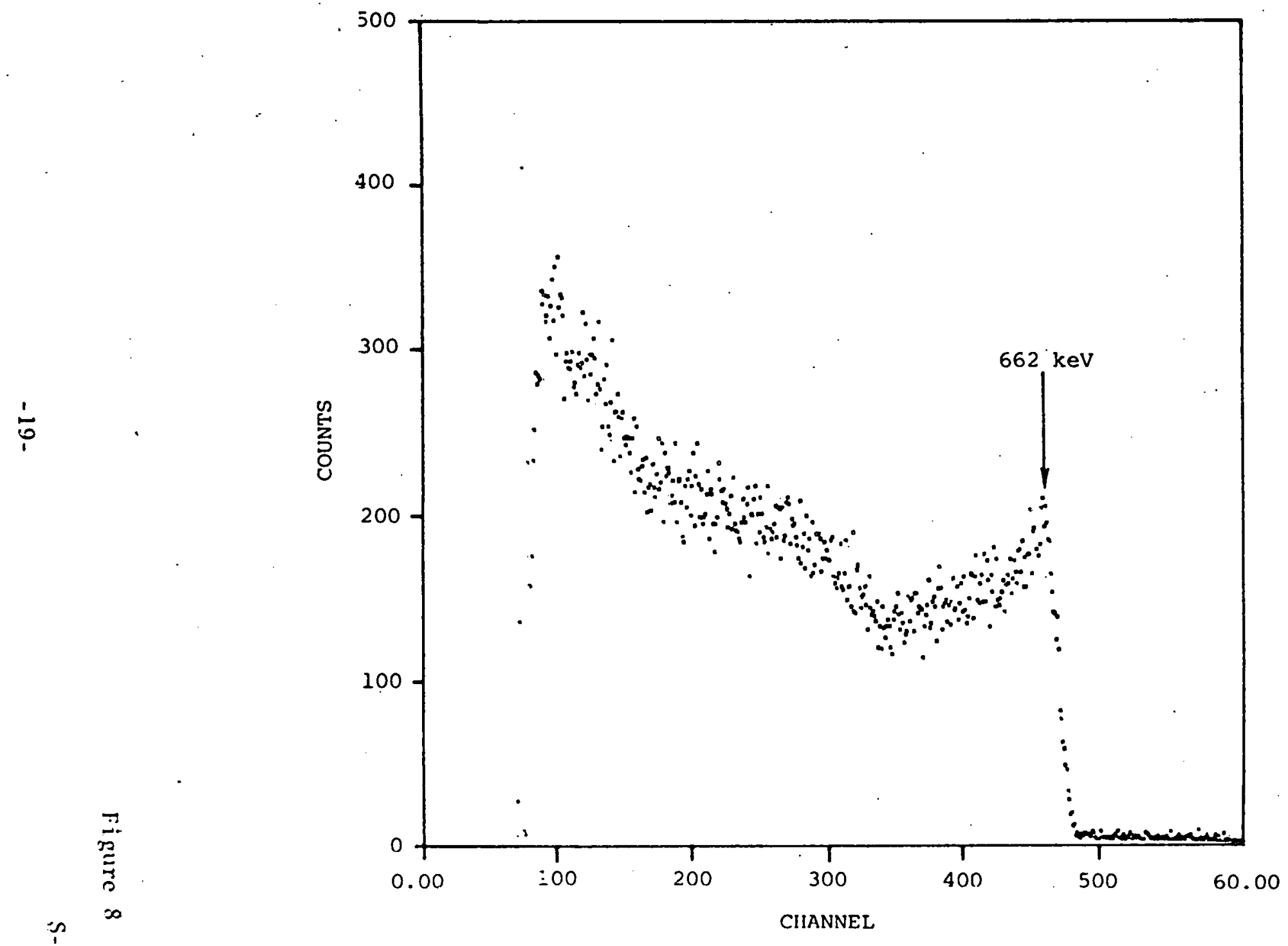




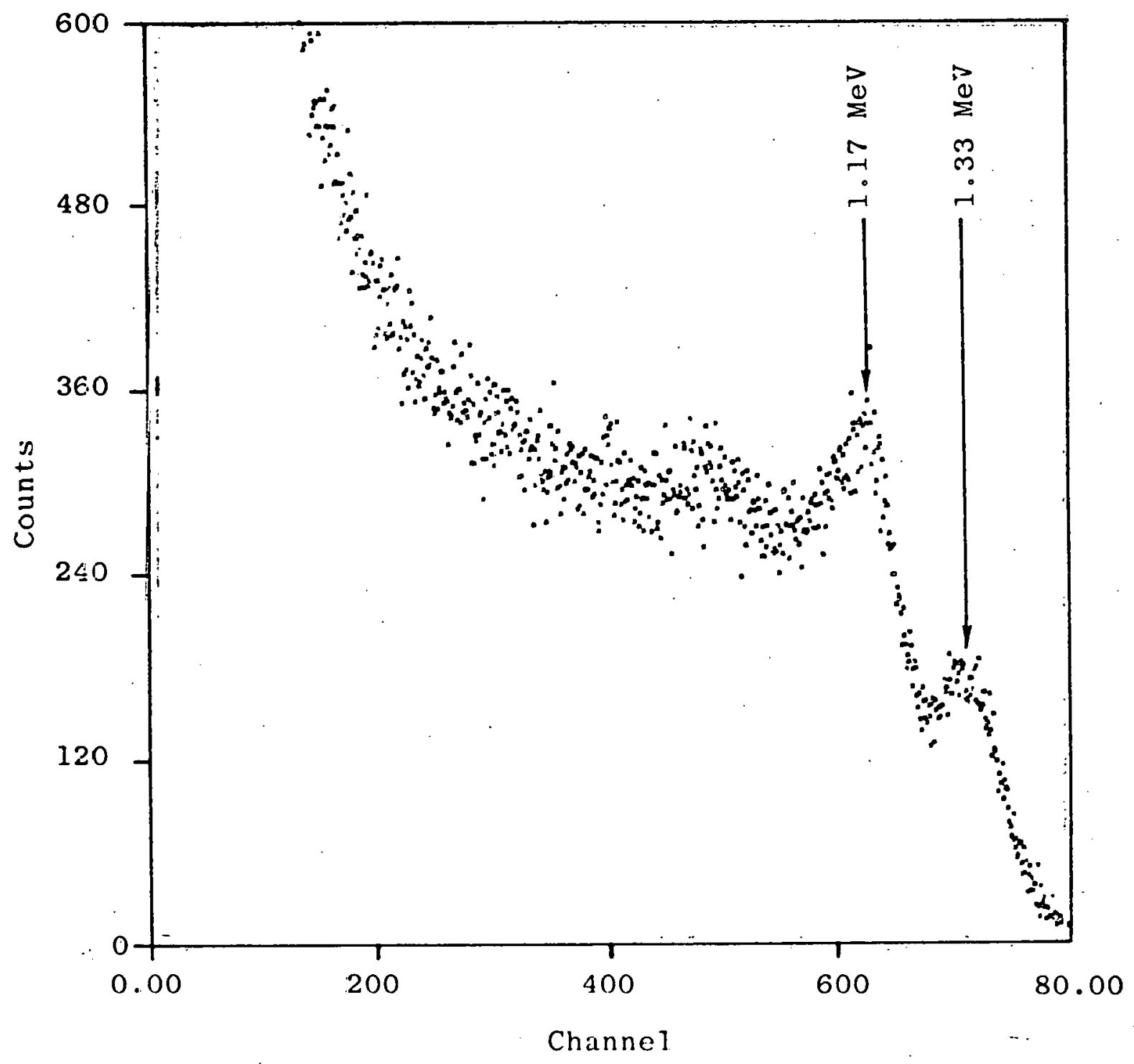

